\title{
Impact of Field Strength and Respiratory Motion Control on Diffusion-Weighted MR Imaging of the Liver
}

\author{
Johanna Berg ${ }^{1,2}$, Sven Månsson ${ }^{1,3}$, Jonas Svensson ${ }^{1,3}$, Olle Ekberg ${ }^{1,2}$, Markus F. Müller ${ }^{1,2}$ \\ ${ }^{1}$ Skåne University Hospital, Department of Clinical Sciences, Lund University, Malmö, Sweden \\ ${ }^{2}$ Medical Radiology, Lund University, Malmö, Sweden \\ ${ }^{3}$ Medical Radiation Physics, Lund University, Malmö, Sweden \\ Email: markus.muller@med.lu.se
}

Received December 10, 2012; revised January 20, 2013; accepted February 1, 2013

\begin{abstract}
Purpose: To evaluate the impact of field strength and respiratory motion control on diffusion-weighted MR imaging (DWI) of the liver at 1.5 and 3 T. Material and Methods: Three DWI sequences using seven $b$-values from $20-400$ $\mathrm{s} / \mathrm{mm}^{2}$ were designed with identical parameters but with different handling of respiratory motion [respiratory triggered (RT), free breathing (FB), breath hold (BH)] on $3 \mathrm{~T}$ and $1.5 \mathrm{~T}$. Thirteen volunteers were examined at a $3 \mathrm{~T}$ and six of them also at a $1.5 \mathrm{~T}$ magnet. DW images were analyzed quantitatively and qualitatively. Regions of interest were placed in cranial, middle and caudal parts of the right liver lobe (RLL) and ADC and SNR were calculated. Results: ADC in RLL tended to be lower at 3 T MRI. Least inter-subject ADC variability was found with RT in the middle RLL at $3 \mathrm{~T}$. Highest ADCs were found caudally in the RLL. Significant differences in ADC between middle and caudal RLL were calculated in FB and RT at $3 \mathrm{~T}$ and FB and BH at $1.5 \mathrm{~T}$, respectively. No significant difference in SNR was found between $3 \mathrm{~T}$ and $1.5 \mathrm{~T}$. There were significantly more artifacts in the left liver lobe (LLL) compared to the RLL in all sequences and in the LLL at $3 \mathrm{~T}$ compared to $1.5 \mathrm{~T}$. Conclusion: Our study suggests that longitudinal hepatic ADC measurements should be performed using equivalent field strength, $b$-values, and acquisition technique, given influence of these factors on ADC measurements.
\end{abstract}

Keywords: Magnetic Resonance Imaging; Diffusion; Echo-Planar Imaging; 3 T; Liver; Respiratory Motion

\section{Introduction}

MR imaging is the only method available today which can evaluate the molecular diffusion process in vivo noninvasively. Recent improvements in hard and soft ware made it possible to add DWI to several clinical body MR imaging protocols, mainly in patients with oncologic problems [1-3]. In addition, the potential of DWI has sparked interest in evaluating diffuse and focal liver disease [4], as metabolic, infectious and malignant diseases may involve the liver.

Previously, most liver DWI studies have been conducted at $1.5 \mathrm{~T}$. Different DWI techniques, such as breath-hold (BH), respiratory-triggered (RT) or free breathing (FB) [5-8], were employed. Most commonly, single-shot spin-echo echo-planar (SE-EPI) sequences under breath-holding were used, but no consensus exists on which technique is most appropriate. Only very few DWI studies were performed at a magnetic field strength of 3 T, either with RT [9] or FB [10]. Works conducted in normal subjects comparing the ADCs in the right liver lobe (RLL) on $3 \mathrm{~T}$ and $1.5 \mathrm{~T}$ have resulted in partly contradictory conclusions, specifically, one study observed that the $\mathrm{ADC}$ increased at $3 \mathrm{~T}$ compared to $1.5 \mathrm{~T}$ [11], whereas another study found the ADC to decease at $3 \mathrm{~T}$ compared to $1.5 \mathrm{~T}[12]$.

The benefits of $3 \mathrm{~T}$ MR imaging for the central nervous and musculoskeletal system are well recognized [13]. $3 \mathrm{~T}$ MR imaging offers a potentially up to two-fold increase in signal-to-noise ratio (SNR) compared to $1.5 \mathrm{~T}$ [14]. This could be advantageous for $3 \mathrm{~T}$ DWI of the liver as DWI suffers from a relatively low SNR. On the other hand, potential limitations for body MRI at $3 \mathrm{~T}$ include worse magnetic susceptibility and chemical shift artifacts, longer $\mathrm{T} 1$ and shorter $\mathrm{T} 2$ and $\mathrm{T} 2{ }^{*}$ relaxation times, 4-fold higher radiofrequency (RF) power deposition that impairs pulse sequence performance because of specific absorption rates limits, and increased B1 field inhomogeneities $[9,15]$. In addition, as the liver borders on gascontaining lung and peristaltic gas-containing bowel loops, the peripheral parts of the liver could be even more prone to artifacts. Furthermore, artifacts from respiratory motion and cardiac pulsation could negatively influence diffusion measurements. These limitations could potentially impair or even undo the SNR advantage of $3 \mathrm{~T}$. 
To our knowledge, there is only little data and partly contradictory conclusions in the literature regarding comparison of DWI of the liver at $3 \mathrm{~T}$ versus $1.5 \mathrm{~T}[11,12]$. A discrepancy in ADC values between field strengths would limit the general applicability of the results, e.g. in follow-up evaluations of diffuse liver disease or liver lesions.

Therefore, the purpose of our study was to evaluate the impact of field strength and respiratory motion control on DWI of the liver. To do this we created a RT, a FB, and a $\mathrm{BH}$ DWI protocol that was applied to healthy volunteers at both $1.5 \mathrm{~T}$ and $3 \mathrm{~T}$.

\section{Material and Methods}

The study was approved by the institutional review board and all volunteers provided informed consent.

\subsection{DWI Sequence Design}

All examinations were performed at a $3 \mathrm{~T}$ and a $1.5 \mathrm{~T}$ system (Magnetom Trio and Avanto, Siemens Healthcare, Erlangen, Germany). A six-channel body and a twelvechannel spine matrix coil were combined for all measurements at both field strengths. The scanner software version at the time of the study was syngo VB15 for both scanners.

For measurement of the apparent diffusion coefficient (ADC) in the liver, three pulse sequences with different strategies for handling of respiratory motion were designed (Table 1):

RT: A SE-EPI sequence acquired under free breathing with prospective acquisition correction (PACE) navigator respiratory triggering technique.

FB: A SE-EPI sequence acquired under free breathing.

BH: A SE-EPI sequence acquired during breath hold. One $b$-value was acquired during each breath hold and the sequence was repeated 7 times with a 15 -second interval between successive scans.

Seven $b$-values were acquired for each sequence (20, $30,40,50,100,200$, and $400 \mathrm{~s} / \mathrm{mm}^{2}$ ). To minimize potential effects of diffusion anisotropy, data was acquired in the 3-scan trace mode. Images were acquired in axial orientation. On a large phantom, the free diffusion coefficient of water was measured at room temperature within the range of $2.00-2.06\left(\times 10^{-3} \mathrm{~mm}^{2} / \mathrm{s}\right)$ for all sequences and at both field strengths.

\subsection{Subjects}

Thirteen healthy volunteers (8 men, 5 women; age 25 52 , mean age 32 ) were included in the study and examined at $3 \mathrm{~T}$. In a subgroup, six subjects ( 3 men, 3 women, age 26 - 29, mean age 26.5) were examined at both $3 \mathrm{~T}$ and $1.5 \mathrm{~T}$ on separate dates (range 3 - 5 days).

\subsection{Data Analysis}

MR images were reviewed and analyzed quantitatively as well as qualitatively.

The ADCs were determined from the slope of a linear regression line fitted from the natural logarithm of the signal intensity $(\mathrm{SI})$ as a function of $b$-value $(\ln (\mathrm{SI})=$ ADC $\cdot b+$ const). The $r^{2}$ value as a measure of the goodness of fit for the linear regression was noted (Figure 1). For this purpose, ROIs of at least 60 pixels in size

Table 1. Sequence parameters for $3 \mathrm{~T}$ and $1.5 \mathrm{~T}$ DWI.

\begin{tabular}{|c|c|c|c|c|c|c|}
\hline \multirow{2}{*}{ Parameter } & \multicolumn{2}{|c|}{ RT } & \multicolumn{2}{|c|}{$\mathrm{FB}$} & \multicolumn{2}{|c|}{$\mathrm{BH}$} \\
\hline & $3 \mathrm{~T}$ & $1.5 \mathrm{~T}$ & $3 \mathrm{~T}$ & $1.5 \mathrm{~T}$ & $3 \mathrm{~T}$ & $1.5 \mathrm{~T}$ \\
\hline $\mathrm{TR}[\mathrm{ms}]$ & $>3500^{\mathrm{b}}$ & $>3500^{\mathrm{b}}$ & 2000 & 2000 & 2000 & 2000 \\
\hline $\mathrm{TE}[\mathrm{ms}]$ & 60 & 60 & 60 & 60 & 60 & 60 \\
\hline Echo train length & $41^{\mathrm{a}}$ & $41^{\mathrm{a}}$ & $41^{\mathrm{a}}$ & $41^{\mathrm{a}}$ & $41^{\mathrm{a}}$ & $41^{\mathrm{a}}$ \\
\hline Matrix & $128 \times 64$ & $128 \times 66$ & $128 \times 64$ & $128 \times 66$ & $128 \times 64$ & $128 \times 66$ \\
\hline $\mathrm{FOV}[\mathrm{mm}]$ & $350 \times 240$ & $350 \times 240$ & $350 \times 240$ & $350 \times 240$ & $350 \times 240$ & $350 \times 240$ \\
\hline Number of slices & 12 & 12 & 12 & 12 & 12 & 12 \\
\hline Slice thickness [mm] & 5 & 5 & 5 & 5 & 5 & 5 \\
\hline Interslice gap [mm] & 2.5 & 2.5 & 2.5 & 2.5 & 2.5 & 2.5 \\
\hline $\begin{array}{l}\text { Fat suppression } \\
\text { Parallel imaging }\end{array}$ & $\begin{array}{l}\text { SPAIR } \\
\text { none }\end{array}$ & $\begin{array}{l}\text { SPAIR } \\
\text { none }\end{array}$ & $\begin{array}{l}\text { SPAIR } \\
\text { none }\end{array}$ & $\begin{array}{l}\text { SPAIR } \\
\text { none }\end{array}$ & $\begin{array}{l}\text { SPAIR } \\
\text { none }\end{array}$ & $\begin{array}{l}\text { SPAIR } \\
\text { none }\end{array}$ \\
\hline Respiratory control & Trigger on & Trigger on & Off & Off & Off & Off \\
\hline Acquisition time [min:s] & $\approx 4: 55^{\mathrm{b}}$ & $\approx 4: 55^{\mathrm{b}}$ & $3: 24$ & $3: 24$ & $0: 22$ & $0: 22$ \\
\hline
\end{tabular}

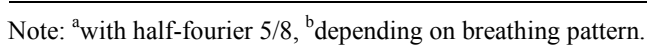




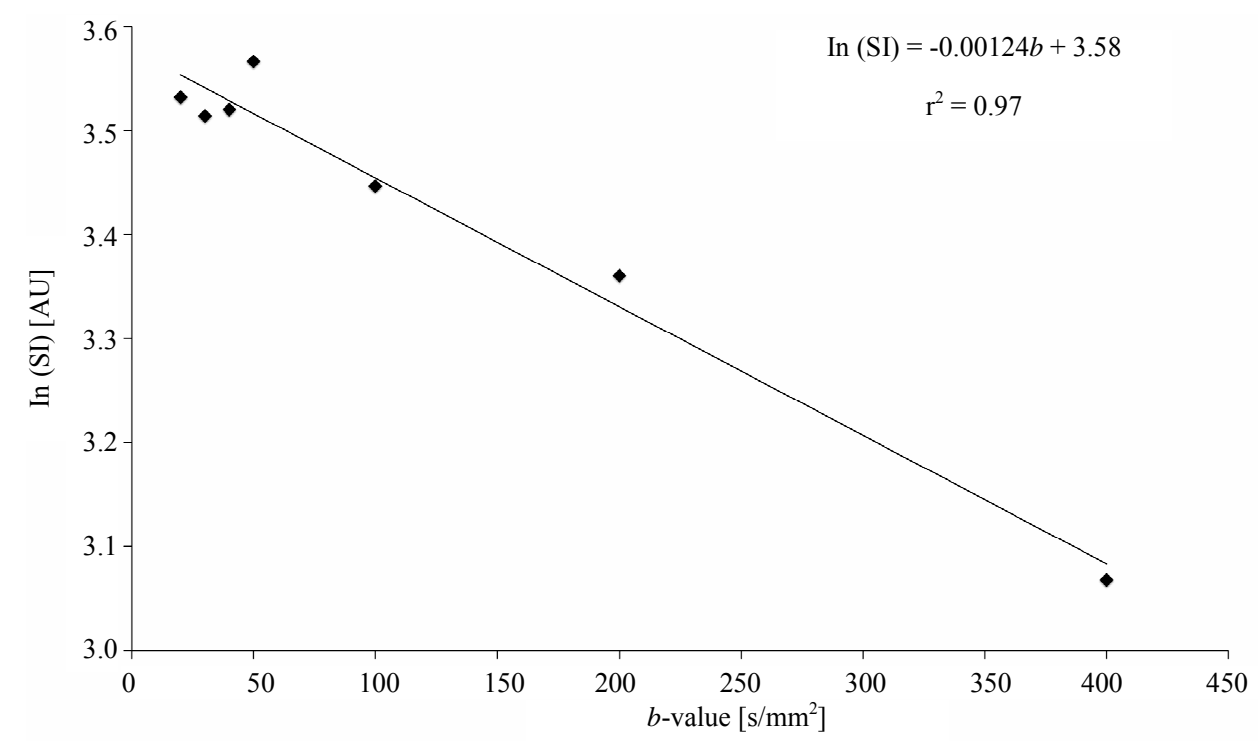

Figure 1. Graph of a typical example for the calculation of the ADC in the middle RLL using the breath hold-type sequence: The ADCs were determined from the slope of a linear regression line fitted from the natural logarithm of the signal intensity (SI) as a function of $b$-value $(\ln (\mathrm{SI})=\mathrm{ADC} \cdot \boldsymbol{b}+$ const $)$. The $r^{2}$ value as a measure of the goodness of fit for the linear regression is also indicated.

were placed in the cranial, middle, and caudal part of the right liver lobe (RLL). Comparable regions were used on both $3 \mathrm{~T}$ and $1.5 \mathrm{~T}$. Great care was taken to place the ROIs in homogeneous areas that were free of visible vessels. The ROIs in the cranial and caudal part of the RLL were placed at least $1 \mathrm{~cm}$ from the liver capsule to minimize influence from artifacts on signal near the liver surface. In two volunteers, ADC calculation was also performed in the left liver lobe (LLL) [RLL and LLL were defined by the portal branching and liver veins according to Couinaud [16]]. SNR was determined for $b$ values $=20$ and $400 \mathrm{~s} / \mathrm{mm}^{2}$ by dividing the mean liver SI with the standard deviation (SD) in an artifact-free area of the background noise.

For qualitative analysis the images were reviewed on a PACS workstation (IDS7, Sectra, Sweden) in random order. Subject information was removed, and the two readers (JB, MFM) were unaware of the magnetic field strengths used to generate the images. Both radiologists gave an independent reading. Qualitative analysis was performed separately and independently from the quantitative analysis. All evaluations were categorized and documented by using standardized data sheets. Overall image quality assessment for each sequence type was evaluated in the RLL and LLL. In addition, each of the following criteria including motion/pulsation artifacts, image distortion, magnetic susceptibility artifacts, chemical shift and ghosting were subjectively graded using a 4-point rating scale from 1 to 4 , referring to 1) poor quality: not diagnostic; 2) fair quality: RLL and/or LLL visible with substantial artifacts; 3) good quality: RLL and/ or LLL adequately seen, few artifacts; and 4) excellent quality: no artifacts seen. Before qualitative analysis was carried out, the two radiologists analyzed a separate set of training cases with agreed-upon ratings conjointly.

\subsection{Statistical Analysis}

For the RLL and LLL at both magnetic field strengths, primary dependent measures for statistical analyses included SNR, ADC values, and $r^{2}$ of the regression line $\ln (\mathrm{SI})$ vs $b$-value. These measurements obtained with each imaging sequence were submitted to separate repeated measures of analysis with field strength and location within the liver. In addition, the averaged ADC values from the different location in RLL were compared between the FB, RT, and BH type sequences. Wilcoxon signed rank test was used to compare these quantitative parameters and the qualitative ratings. Differences of ADC measurements between $3 \mathrm{~T}$ and $1.5 \mathrm{~T}$ were calculated and Bland-Altman plots generated. Agreement between the two readers in terms of image quality scores was assessed by weighted specific-category kappa measure. A significance level of $\leq 0.05$ was used for all analyses. The standard deviation (SD) of the ADC values was used as a measure of the inter-individual variation.

\section{Results}

The ADCs and the inter-individual ADC variation (SD) tended to be lower at $3 \mathrm{~T}$ than at $1.5 \mathrm{~T}$. The lowest variation was obtained with the RT measurement in the middle RLL at $3 \mathrm{~T}$.

Generally, the artifacts were worse at $3 \mathrm{~T}$ compared to at $1.5 \mathrm{~T}$ (Table 2, Figure 2). There were more artifacts 
Table 2. Comparison of average artifact score (SD) between $3 \mathrm{~T}$ and $1.5 \mathrm{~T}$ for each sequence type.

\begin{tabular}{ccccccccc}
\hline & \multicolumn{3}{c}{$3 \mathrm{~T}$} & \multicolumn{3}{c}{$1.5 \mathrm{~T}$} & \multicolumn{2}{c}{$\mathrm{p}$} \\
\cline { 2 - 8 } & $\mathrm{LLL}$ & $\mathrm{RLL}$ & $\mathrm{p}$ & LLL & RLL & $\mathrm{p}$ & LLL 3 T vs 1.5 T & RLL 3 T vs 1.5 T \\
\hline RT & $1.5(0.5)$ & $2.2(0.4)$ & $<0.01$ & $2.1(0.5)$ & $2.9(0.3)$ & $<0.01$ & $<0.01$ & $<0.01$ \\
FB & $1.6(0.5)$ & $2.6(0.7)$ & $<0.01$ & $2.0(0.6)$ & $3.0(0.4)$ & $<0.01$ & 0.03 & 0.06 \\
BH & $1.8(0.4)$ & $2.8(0.5)$ & $<0.01$ & $2.2(0.4)$ & $3.0(0)$ & $<0.01$ & 0.05 & 0.08 \\
\hline
\end{tabular}

Note: Values presented as mean (SD). LLL denotes left liver lobe, RLL right liver lobe.

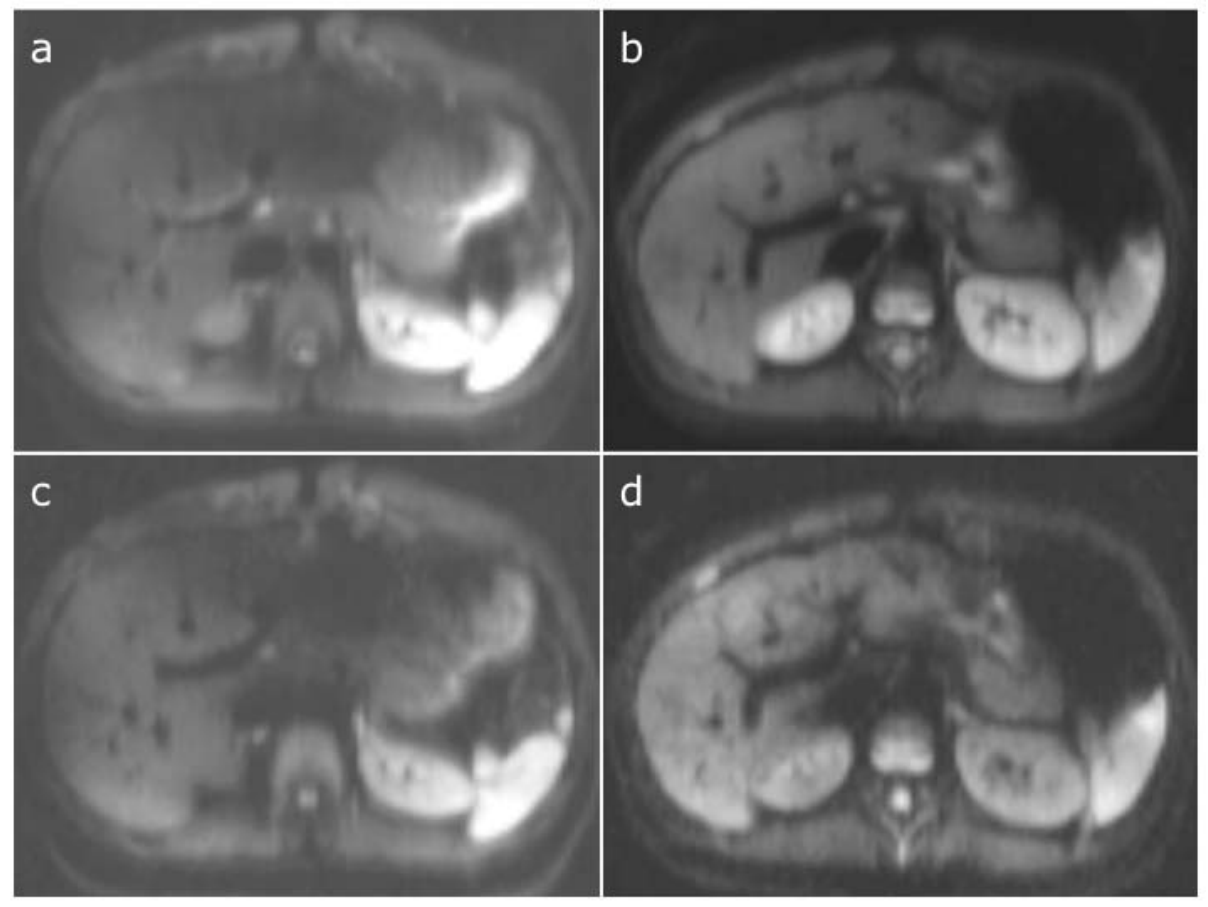

Figure 2. Representative images that compare image quality at $3 \mathrm{~T}$ (a and c) with $1.5 \mathrm{~T}$ (b and c) obtained at $b=20$ (a and $b$ ) and $b=400 \mathrm{~s} / \mathrm{mm}^{2}$ (c and d). Note the more pronounced susceptibility and motion artifacts in the LLL at $3 \mathrm{~T}$.

$(p<0.01)$ in the LLL compared to the RLL in all three sequence types at both $3 \mathrm{~T}$ and $1.5 \mathrm{~T}$. In addition, there were significantly more artifacts in the LLL at $3 \mathrm{~T}$ compared to $1.5 \mathrm{~T}$. There was a good agreement between the two observers for image quality assessment (weighted kappa coefficient $=0.72$ ).

There was no significant difference in SNR between 3 $\mathrm{T}$ and $1.5 \mathrm{~T}$, and between the three types of imaging sequences, measured for $b$-values of 20 and $400 \mathrm{~s} / \mathrm{mm}^{2}$, respectively (Table 3 ).

The ADCs in the middle, cranial and caudal part of the RLL for the different types of diffusion-weighted sequences at $3 \mathrm{~T}$ and $1.5 \mathrm{~T}$ are compiled in Table 4 and graphically displayed in Figure 3. The $r^{2}$ of the ADC fits were excellent and ranged from $0.92-0.99$ and no significant difference was found between $3 \mathrm{~T}$ and $1.5 \mathrm{~T}$. There was considerable variation of the ADCs based on the magnetic field strength ( $3 \mathrm{~T}$ vs $1.5 \mathrm{~T})$, type of sequence $(\mathrm{FB}, \mathrm{RT}, \mathrm{BH})$ applied, and location within the
RLL (see Figure 3). Generally, the ADCs tended to be lower on $3 \mathrm{~T}$ than on $1.5 \mathrm{~T}$ (Figure 4), but were only significantly lowered with RT in the middle RLL. The mean ADC differences between $1.5 \mathrm{~T}$ and $3 \mathrm{~T}$ (SD; $95 \%$ confidence intervals) were for FB cranial $0.20(0.4 ;-0.2$, $0.6)$, RT cranial $0.13(0.2 ;-0.1,0.31), \mathrm{BH}$ cranial 0.03 $(0.3 ;-0.2,0.3)$, FB middle $0.11(0.6 ;-0.5,0.7)$, RT middle $0.21(0.2 ;-0.04,0.4)$, BH middle $0.04(0.5 ;-0.5$, $0.5)$, FB caudal $0.14(0.2 ;-0.1,0.4)$, RT caudal $0.11(0.2$; $-0.1,0.4)$, and BH caudal $0.17(0.4 ;-0.2,0.5) \times 10^{-3}$ $\mathrm{mm}^{2} / \mathrm{s}$. Thus the ADCs at $1.5 \mathrm{~T}$ were higher compared to $3 \mathrm{~T}$.

The least inter-subject ADC variability was obtained with RT at both field strengths, especially at $3 \mathrm{~T}$ in the middle of the RLL. The highest ADCs were found caudally in the RLL, both at $3 \mathrm{~T}$ and $1.5 \mathrm{~T}$. Significant differences in ADC between middle and caudal part of the RLL were found in RT and FB at $3 \mathrm{~T}$ and $\mathrm{FB}$ and $\mathrm{BH}$ at $1.5 \mathrm{~T}$, respectively (Table $4(\mathbf{a})$ ). Even averaging of the 
Table 3. (a) Comparison of SNR measured in three different locations in the right liver lobe between $3 \mathrm{~T}$ and $1.5 \mathrm{~T}$ for $\mathrm{b}=\mathbf{2 0}$ $\mathrm{s} / \mathrm{mm}^{2}$; (b) Comparison of SNR measured in three different locations in the right liver lobe between $3 \mathrm{~T}$ and $1.5 \mathrm{~T}$ for $\mathrm{b}=400$ $\mathbf{s} / \mathbf{m m}^{2}$.

(a)

\begin{tabular}{|c|c|c|c|c|c|c|}
\hline \multirow[b]{2}{*}{ Location } & \multirow[b]{2}{*}{ Type } & \multicolumn{2}{|c|}{ mean } & \multicolumn{2}{|c|}{ SD } & \multirow[t]{2}{*}{$\mathrm{p}$} \\
\hline & & $3 \mathrm{~T}$ & $1.5 \mathrm{~T}$ & $3 \mathrm{~T}$ & $1.5 \mathrm{~T}$ & \\
\hline \multirow{3}{*}{ Middle } & FB & 46 & 68 & 18 & 19 & 0.39 \\
\hline & $\mathrm{RT}$ & 55 & 66 & 19 & 12 & 0.65 \\
\hline & $\mathrm{BH}$ & 47 & 60 & 21 & 14 & 0.98 \\
\hline \multirow{3}{*}{ Cranial } & FB & 53 & 64 & 24 & 15 & 0.90 \\
\hline & RT & 59 & 62 & 25 & 11 & 0.75 \\
\hline & $\mathrm{BH}$ & 51 & 62 & 30 & 12 & 0.53 \\
\hline \multirow{3}{*}{ Caudal } & FB & 47 & 70 & 22 & 21 & 0.60 \\
\hline & $\mathrm{RT}$ & 63 & 71 & 27 & 15 & 0.78 \\
\hline & $\mathrm{BH}$ & 47 & 61 & 23 & 17 & 0.98 \\
\hline
\end{tabular}

Note: middle, cranial, and caudal denote the location of the ROI in the right liver lobe.

(b)

\begin{tabular}{|c|c|c|c|c|c|c|}
\hline \multirow[b]{2}{*}{ Location } & \multirow[b]{2}{*}{ Type } & \multicolumn{2}{|c|}{ mean } & \multicolumn{2}{|c|}{ SD } & \multirow[t]{2}{*}{$\mathrm{p}$} \\
\hline & & $3 \mathrm{~T}$ & $1.5 \mathrm{~T}$ & $3 \mathrm{~T}$ & $1.5 \mathrm{~T}$ & \\
\hline \multirow{3}{*}{ Middle } & FB & 26 & 36 & 9 & 9 & 0.52 \\
\hline & RT & 34 & 36 & 14 & 7 & 0.99 \\
\hline & $\mathrm{BH}$ & 29 & 36 & 10 & 10 & 0.64 \\
\hline \multirow{3}{*}{ Cranial } & FB & 32 & 32 & 14 & 7 & 0.43 \\
\hline & RT & 36 & 35 & 16 & 7 & 0.68 \\
\hline & $\mathrm{BH}$ & 30 & 34 & 12 & 9 & 0.71 \\
\hline \multirow{3}{*}{ Caudal } & FB & 26 & 32 & 12 & 8 & 0.91 \\
\hline & RT & 36 & 38 & 19 & 10 & 0.86 \\
\hline & $\mathrm{BH}$ & 28 & 31 & 11 & 9 & 0.89 \\
\hline
\end{tabular}

Note: middle, cranial, and caudal denote the location of the ROI in the right liver lobe.

three locations in the RLL using FB, RT, and BH type sequences at $3 \mathrm{~T}$ and $1.5 \mathrm{~T}$ revealed significantly lower ADC-values at $3 \mathrm{~T}$ (Table 4(b)).

In two representative volunteers the $\mathrm{ADC}$ was also calculated for the LLL. Mean ADC was higher in the LLL than RLL for all three sequence types and both magnetic field strengths. In the LLL, the ADCs were in the range of $2.0-2.1(3 \mathrm{~T})$ and $2.0-2.6(1.5 \mathrm{~T}) \times 10^{-3}$ $\mathrm{mm}^{2} / \mathrm{s}$. The corresponding values for the middle RLL were $1.3-1.4(3 \mathrm{~T})$ and $1.4-1.7(1.5 \mathrm{~T}) \times 10^{-3} \mathrm{~mm}^{2} / \mathrm{s}$.

\section{Discussion}

We sought to determine the impact of respiratory control and field strength on the quality of DWI of the liver. Generally, the RT sequence performed somewhat better than FB and $\mathrm{BH}$ in terms of inter-individual variation of the ADC values. As for choice of field strength, no clear difference in inter-individual variation between $1.5 \mathrm{~T}$ and $3 \mathrm{~T}$ was seen. The lowest variation was however found for RT acquisition in the middle RLL at $3 \mathrm{~T}$.

Image quality was generally rather poor in the LLL at both $1.5 \mathrm{~T}$ and $3 \mathrm{~T}$. For the RLL image quality was considered somewhat better at $1.5 \mathrm{~T}$ compared with $3 \mathrm{~T}$.

There was no advantage of SNR in the examination of the volunteers at $3 \mathrm{~T}$ over $1.5 \mathrm{~T}$. Previous studies have indicated a much shorter $\mathrm{T}_{2}$ relaxation time in the liver at $3 \mathrm{~T}$, which likely explains the lack of SNR-improvement at $3 \mathrm{~T}[17,18]$.

Our results indicate that the ADC cannot be measured reliably in the LLL as susceptibility and motion artifacts may dominate. Motion artifacts propagated from the contracting heart and pulsating aorta may induce substantial signal loss in diffusion-weighted images depending on the cardiac phase $[19,20]$ and may impair reliability and reproducibility of ADC measurements of liver parenchyma and lesions. Not surprisingly, only very few articles discuss this issue or demonstrate images with pathology in the left liver lobe [4,21-23]. Subjective quali- 
Table 4. (a) Comparison of ADC values $\left[\times 10^{-3} \mathrm{~mm}^{2} / \mathrm{s}\right]$ using FB, RT, BH type sequences measured in three different locations in the right liver lobe at $3 \mathrm{~T}$ and $1.5 \mathrm{~T}$; (b) Comparison of ADC values using FB, RT, BH type sequences averaged from middle, cranial, and caudal locations in the right liver lobe at $3 \mathrm{~T}$ and $1.5 \mathrm{~T}$.

(a)

\begin{tabular}{|c|c|c|c|c|c|c|}
\hline \multirow[b]{2}{*}{ Location } & \multirow[b]{2}{*}{ Type } & \multicolumn{2}{|c|}{ Mean ADC } & \multicolumn{2}{|c|}{ SD } & \multirow[t]{2}{*}{$\mathrm{p}$} \\
\hline & & $3 \mathrm{~T}$ & $1.5 \mathrm{~T}$ & $3 \mathrm{~T}$ & $1.5 \mathrm{~T}$ & \\
\hline \multirow{3}{*}{ Middle } & $\mathrm{FB}$ & 1.38 & 1.53 & 0.22 & 0.34 & 0.35 \\
\hline & $\mathrm{RT}$ & 1.41 & 1.65 & 0.09 & 0.17 & 0.04 \\
\hline & $\mathrm{BH}$ & 1.30 & 1.43 & 0.31 & 0.34 & 0.92 \\
\hline \multirow{3}{*}{ Cranial } & FB & 1.42 & 1.61 & 0.23 & 0.14 & 0.17 \\
\hline & $\mathrm{RT}$ & 1.48 & 1.66 & 0.17 & 0.22 & 0.12 \\
\hline & $\mathrm{BH}$ & 1.35 & 1.53 & 0.29 & 0.15 & 0.92 \\
\hline \multirow{3}{*}{ Caudal } & FB & 1.64 & 1.88 & 0.20 & 0.26 & 0.17 \\
\hline & $\mathrm{RT}$ & 1.59 & 1.74 & 0.19 & 0.16 & 0.25 \\
\hline & $\mathrm{BH}$ & 1.42 & 1.73 & 0.27 & 0.17 & 0.25 \\
\hline
\end{tabular}

Note: middle, cranial, and caudal denote the location of the ROI in the right liver lobe. ADC, SD: inter-individual mean and standard deviation.

(b)

\begin{tabular}{|c|c|c|c|c|c|c|}
\hline & RT $3 \mathrm{~T}$ & FB $3 \mathrm{~T}$ & $\mathrm{BH} 3 \mathrm{~T}$ & RT $1.5 \mathrm{~T}$ & FB $1.5 \mathrm{~T}$ & $\mathrm{BH} 1.5 \mathrm{~T}$ \\
\hline Mean & 1.49 & 1.49 & 1.36 & 1.68 & 1.67 & 1.56 \\
\hline SEM & 0.03 & 0.04 & 0.05 & 0.04 & 0.07 & 0.06 \\
\hline Median & 1.47 & 1.48 & 1.37 & 1.65 & 1.65 & 1.54 \\
\hline SD & 0.17 & 0.22 & 0.29 & 0.18 & 0.29 & 0.26 \\
\hline Minimum & 1.08 & 1.00 & 0.68 & 1.44 & 1.10 & 1.18 \\
\hline Maximum & 1.96 & 2.09 & 1.86 & 2.04 & 2.23 & 2.11 \\
\hline
\end{tabular}

Note: $\mathrm{SEM}=$ Standard Error of Mean, $\mathrm{SD}=$ Std. Deviation. Significant differences in ADC were found in RT 3 T vs RT $1.5 \mathrm{~T}(\mathrm{p}=0.01)$, RT 3 T vs FB $1.5 \mathrm{~T}$ $(\mathrm{p}=0.03)$, RT $3 \mathrm{~T}$ vs BH $3 \mathrm{~T}(\mathrm{p}=0.01)$, FB $3 \mathrm{~T}$ vs BH $3 \mathrm{~T}(\mathrm{p}<0.01)$, BH 3 T vs RT $1.5 \mathrm{~T}(\mathrm{p}=0.03)$, BH 3 T vs FB $1.5 \mathrm{~T}(\mathrm{p}=0.03)$, and FB $1.5 \mathrm{~T}$ vs BH 1.5 $\mathrm{T}(\mathrm{p}=0.05)$.

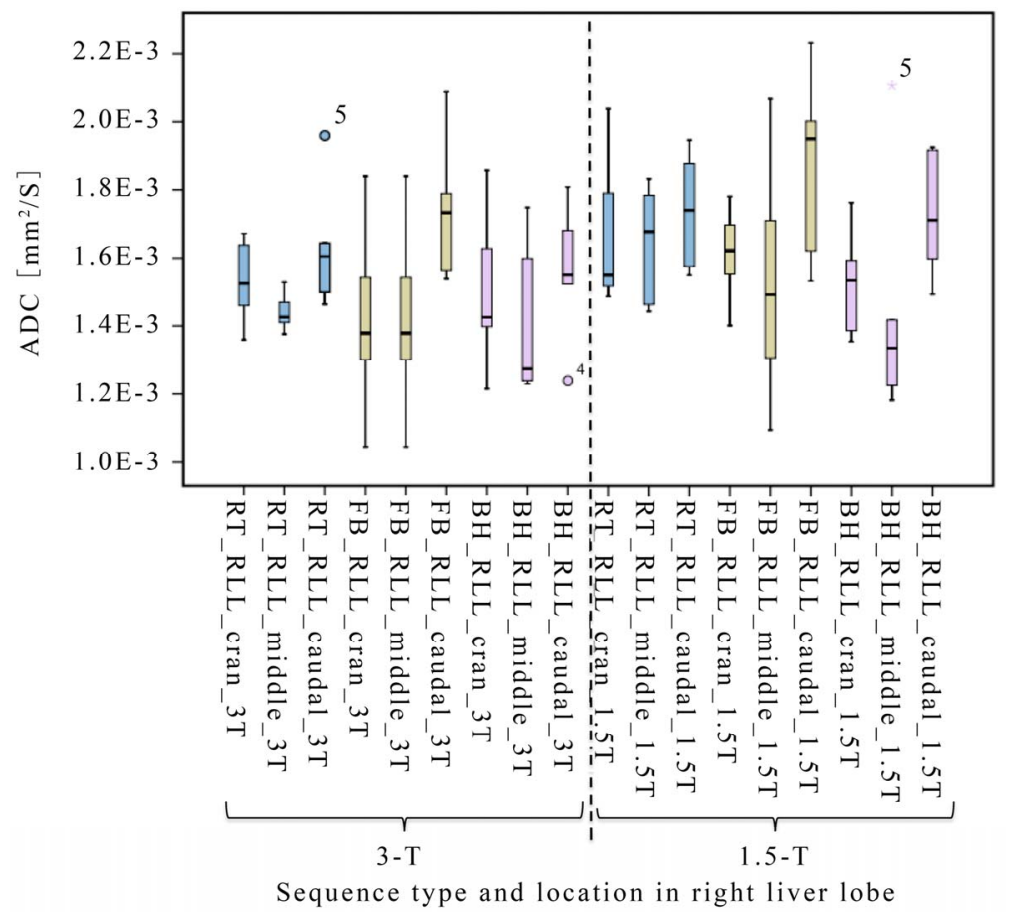

Figure 3. Boxplot of ADC values using FB (olive), RT (blue), BH (pink)-type sequences measured in three different locations (cran = cranial, middle, caudal) in the right liver lobe at $3 \mathrm{~T}$ and $1.5 \mathrm{~T}$. Least inter-individual variation (best reproducibility) in ADC is observed in RT at $3 \mathrm{~T}$. 

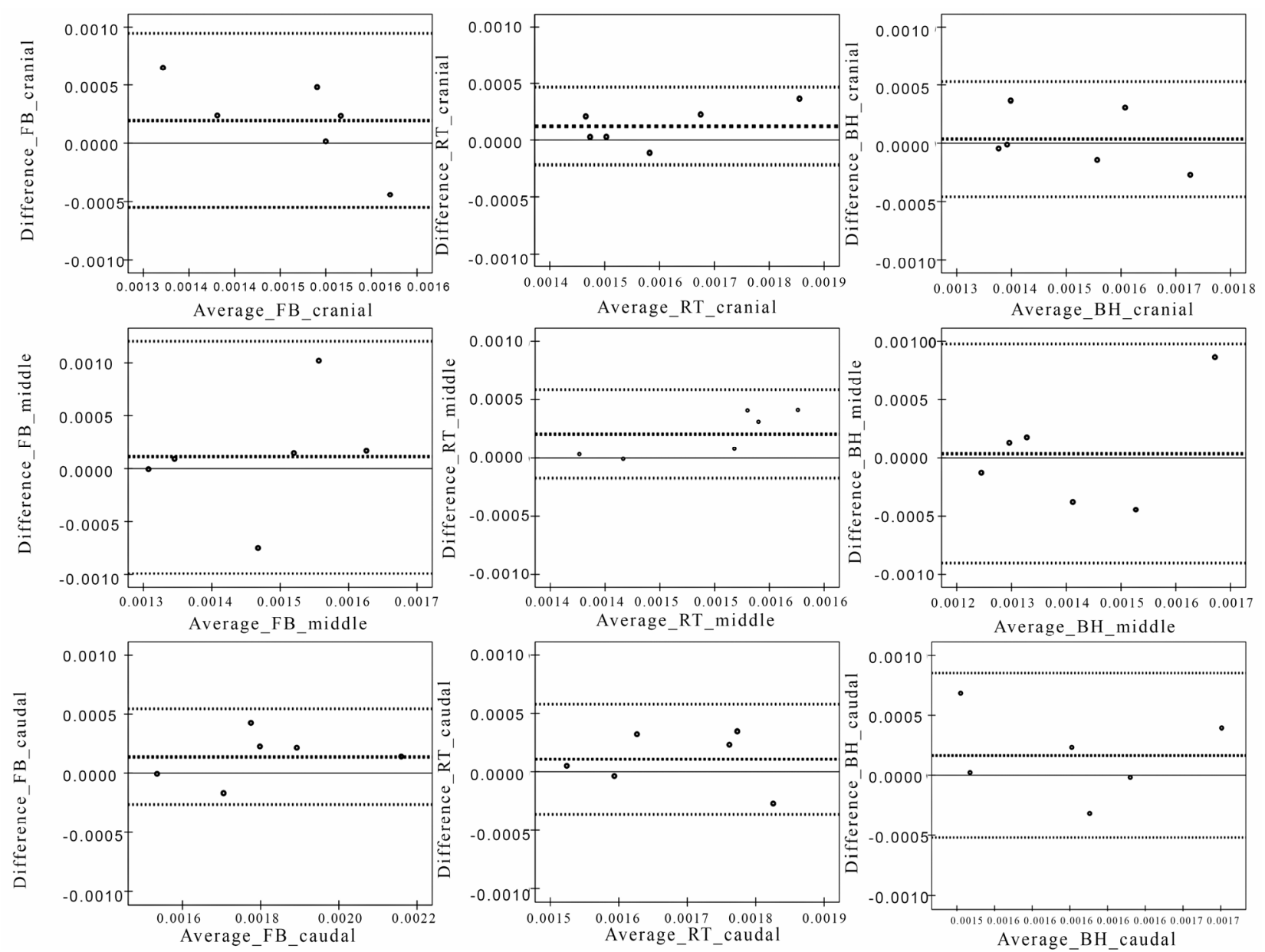

Figure 4. Graphs represent Bland-Altman plots of the difference in $\mathrm{ADC}\left[\mathrm{mm}^{2} / \mathrm{s}\right]$ between magnetic field strengths against the average of the ADCs $\left[\mathrm{mm}^{2} / \mathrm{s}\right]$ of the magnetic field strengths of the corresponding respiratory motion control method and location within RLL (lines represent the average ADC and average ADC \pm 2 SD).

tative image analysis showed that these artifacts were even more pronounced at $3 \mathrm{~T}$. This could be an effect of increased chemical-shift and susceptibility, and blooming of gas-containing bowel loops. Hence, calculated ADC are either overestimated [22] or even impossible to measure. For these reasons, we did not perform any further evaluation of the LLL but concentrated on the RLL.

The vast majority of DWI studies of the liver so far have been performed at $1.5 \mathrm{~T}$ and used SE-EPI sequences in combination with fat suppression. A few of these studies explored also whether DWI would best be performed with use of RT, FB or BH acquisitions. Kandpal et al. [22] and Taouli et al. [24] compared RT with $\mathrm{BH}$ acquisitions at $1.5 \mathrm{~T}$ in patients with focal liver lesions. They concluded that RT should be preferred because of better SNR and image quality, but had different statements concerning impact on the calculated ADC values. One reason for their observed superiority of the RT sequence could simply be that they applied $2-3$ times more signal averages in the RT sequences compared with the BH sequences. Kwee et al. [7] compared RT, FB and $\mathrm{BH}$ sequences of the normal liver at $1.5 \mathrm{~T}$ in volunteers. Similar sequence parameters and two signal averages were used. They concluded that ADCs in RT were significantly higher and less reproducible than in FB and $\mathrm{BH}$. In these comparisons, the calculation of the ADCs were based only on $b=0$ plus one [7,22] or two [24] more $b$-values with the highest being $b=500 \mathrm{~s} / \mathrm{mm}^{2}$. In our study, we chose a different approach and used only $b$-values from $20-400 \mathrm{~s} / \mathrm{mm}^{2}$ for the calculation of the ADCs. The reason for doing this was to reduce the contribution from microperfusion. In addition, in order to match the SNR of our RT and FB sequence we segmented the BH sequence in multiple breath holds. As the BH sequences in our implementation were performed with every $b$-value as a separate scan this could have contributed to the variability in ADC. Overall, in accordance with previous studies, the ADCs were inter-individually quite scattered. This scatter can also be observed intra-individually when diffusion is measured with dif- 
ferent sequences. Mean ADC values of normal liver at $1.5 \mathrm{~T}$ reported in the recent literature varied from 0.9 [24] to $2.3[7] \times 10^{-3} \mathrm{~mm}^{2} / \mathrm{s}$.

Braithwaite et al. [10] determined the ADC values in normal liver to $\approx 2.4 \times 10^{-3} \mathrm{~mm}^{2} / \mathrm{s}$ at $3 \mathrm{~T}$ using a stimulated-echo EPI sequence during FB. They applied only 0 plus $400 \mathrm{~s} / \mathrm{mm}^{2}$ as $b$-values which might explain at least partly why our calculated ADCs at $3 \mathrm{~T}$ were much lower. The same researchers compared the ADCs in the liver between $3 \mathrm{~T}$ and $1.5 \mathrm{~T}$ in a different publication and concluded that the ADCs at $3 \mathrm{~T}$ were significantly higher than at $1.5 \mathrm{~T}$ [11]. On the other hand, Rosenkrantz et al. [12] measured much lower ADCs (1.49 $\pm 0.47 \times 10^{-3}$ $\mathrm{mm}^{2} / \mathrm{s}$ ) using similar hard- and software and did not find a significant difference between $3 \mathrm{~T}$ and $1.5 \mathrm{~T}$. As in our study, artifacts were subjectively more pronounced at $3 \mathrm{~T}$ and may have influenced the accuracy of the ADC measurements. However, ADC with low inter-individual scatter and relatively small SD could be calculated in our study in the middle of the RLL with RT at $3 \mathrm{~T}$.

Generally, the ADC values in our study tended to be lower at $3 \mathrm{~T}$ compared to $1.5 \mathrm{~T}$, as hinted in Figure 3. They were significantly lower with RT in the middle of the RLL. The reason for this discrepancy is unknown, but we speculate that it may be related to the shorter $\mathrm{T} 2{ }^{*}$ at 3 $\mathrm{T}$ compared to $1.5 \mathrm{~T}$. The best conditions for calculating the ADCs should be in the middle of the RLL (most homogenous magnetic field and least susceptibility artifacts). This was confirmed with low inter-individual SD of the ADC measurement using RT at $3 \mathrm{~T}$. ADC varied considerably when measured in the cranial and caudal part compared to the central part of the RLL. Mean ADC tended to be higher in the cranial and caudal part compared to the middle part of the RLL at $3 \mathrm{~T}$ as well as at $1.5 \mathrm{~T}$. Significant differences between middle and caudal part of the RLL were found for RT and FB at $3 \mathrm{~T}$ and FB at $1.5 \mathrm{~T}$, respectively. A possible explanation for this may be, besides artifacts from susceptibility, that the liver will be deformed during respiration. This deformation is complex, more pronounced in the caudal part of the RLL, and different during inspiration and expiration, variable between different breathing cycles, and during the drift in the expiration position over time [25]. Furthermore, the caudal part of the RLL can be deformed due to intestinal activity [25]. These resulting motions are far smaller than respiratory movement but may lead to intravoxel phase dispersion and consequently signal loss with artificially increased ADC [26]. Hence, several kinds of artifacts may lead to an overestimation of the calculated ADCs in these regions.

In order to assess diffuse liver disease, an accurate, reproducible and noninvasive test is desirable for early diagnosis and disease monitoring. Our study suggests that ADC measurement using RT in the middle of the
RLL at 3 T could be most accurate. However, image quality of some axial sections can be degraded and ADC calculation in these regions would result in measurement errors. Therefore, great care has to be taken to select standardized ROIs. This fact could pose a problem if ADC has to be recalculated by a different observer or on follow-up examinations possibly resulting in poor reproducibility [27].

Our present study has some limitations. First, our study population was relatively small and consisted only of middle-aged healthy volunteers. Nevertheless, our results may have impact on DWI in patients with diffuse liver disease concerning choice of magnetic field strength, type of DWI acquisition, as well as sampling location.

In summary, ADC values tended to be lower at $3 \mathrm{~T}$ compared to $1.5 \mathrm{~T}$. Least inter-individual variation in ADC was found in middle RLL measured with RT at $3 \mathrm{~T}$. However, measured ADC values of the liver are dependent on the type of DWI sequence, selection of $b$-values, as well as magnetic field strength or a combination of any or all of these factors and sampling location. There may also be an inter-individual physiologic scatter of ADCs. This implies that ADC measurements have to be performed ideally under a standardized manner and are probably best suited for intra-individual follow-up examinations.

\section{REFERENCES}

[1] S. H. Kim, J. M. Lee, S. H. Hong, G. H. Kim, J. Y. Lee, J. K. Han and B. I. Choi, "Locally Advanced Rectal Cancer: Added Value of Diffusion-Weighted MR Imaging in the Evaluation of Tumor Response to Neoadjuvant Chemoand Radiation Therapy," Radiology, Vol. 253, No. 1, 2009, pp. 116-125. doi:10.1148/radiol.2532090027

[2] T. Kwee, T. Takahara, R. Ochiai, R. Nievelstein and P. Luijten, "Diffusion-Weighted Whole-Body Imaging with Background Body Signal Suppression (DWIBS): Features and Potential Applications in Oncology," European Radiology, Vol. 18, No. 9, 2008, pp. 1937-1952. doi:10.1007/s00330-008-0968-Z

[3] R. N. Low and J. Gurney, "Diffusion-Weighted MRI (DWI) in the Oncology Patient: Value of Breathhold DWI Compared to Unenhanced and Gadolinium-Enhanced MRI," Journal of Magnetic Resonance Imaging, Vol. 25, No. 4, 2007, pp. 848-858. doi:10.1002/jmri.20864

[4] M. F. Muller, P. Prasad, B. Siewert, M. A. Nissenbaum, V. Raptopoulos and R. R. Edelman, "Abdominal Diffusion Mapping with Use of a Whole-Body Echo-Planar System," Radiology, Vol. 190, No. 2, 1994, pp. 475-478.

[5] M. Bruegel, K. Holzapfel, J. Gaa, K. Woertler, S. Waldt, B. Kiefer, A. Stemmer, C. Ganter and E. J. Rummeny, "Characterization of Focal Liver Lesions by ADC Measurements Using a Respiratory Triggered Diffusion-Weighted Single-Shot Echo-Planar MR Imaging Technique," European Radiology, Vol. 18, No. 3, 2008, pp. 477-485. doi:10.1007/s00330-007-0785-9 
[6] S. Goshima, M. Kanematsu, H. Kondo, R. Yokoyama, K. Kajita, Y. Tsuge, H. Watanabe, Y. Shiratori, M. Onozuka and N. Moriyama, "Diffusion-Weighted Imaging of the Liver: Optimizing $b$ Value for the Detection and Characterization of Benign and Malignant Hepatic Lesions," Journal of Magnetic Resonance Imaging, Vol. 28, No. 3, 2008, pp. 691-697. doi:10.1002/jmri.21467

[7] T. C. Kwee, T. Takahara, D.-M. Koh, R. A. J. Nievelstein and P. R. Luijten, "Comparison and Reproducibility of ADC Measurements in Breathhold, Respiratory Triggered, and Free-Breathing Diffusion-Weighted MR Imaging of the Liver," Journal of Magnetic Resonance Imaging, Vol. 28, No. 5, 2008, pp. 1141-1148. doi:10.1002/jmri.21569

[8] M. Lewin, A. Poujol-Robert, P. Y. Boelle, D. Wendum, E. Lasnier, M. Viallon, J. Guechot, C. Hoeffel, L. Arrive, J. M. Tubiana and R. Poupon, "Diffusion-Weighted Magnetic Resonance Imaging for the Assessment of Fibrosis in Chronic Hepatitis C," Hepatology, Vol. 46, No. 3, 2007, pp. 658-665. doi:10.1002/hep. 21747

[9] M. K. Ivancevic, T. C. Kwee, T. Takahara, T. Ogino, H. K. Hussain, P. S. Liu and T. L. Chenevert, "Diffusionweighted MR Imaging of the Liver at 3.0 Tesla Using Tracking Only Navigator Echo (TRON): A Feasibility Study," Journal of Magnetic Resonance Imaging, Vol. 30, No. 5, 2009, pp. 1027-1033. doi:10.1002/jmri.21939

[10] A. C. Braithwaite, B. M. Dale, D. T. Boll and E. M. Merkle, "Short- and Midterm Reproducibility of Apparent Diffusion Coefficient Measurements at 3.0-T Diffusion-Weighted Imaging of the Abdomen," Radiology, Vol. 250, No. 2, 2009, pp. 459-465. doi:10.1148/radiol.2502080849

[11] B. M. Dale, A. C. Braithwaite, D. T. Boll and E. M. Merkle, "Field Strength and Diffusion Encoding Technique Affect the Apparent Diffusion Coefficient Measurements in Diffusion-Weighted Imaging of the Abdomen," Investigative Radiology, Vol. 45, No. 2, 2010, pp. 104-108. doi:10.1097/RLI.0b013e3181c8ceac

[12] A. B. Rosenkrantz, M. Oei, J. S. Babb, B. E. Niver and B. Taouli, "Diffusion-Weighted Imaging of the Abdomen at 3.0 Tesla: Image Quality and Apparent Diffusion Coefficient Reproducibility Compared with 1.5 Tesla," Journal of Magnetic Resonance Imaging, Vol. 33, No. 1, 2011, pp. 128-135. doi:10.1002/jmri.22395

[13] J. Zhao, R. Krug, D. Xu, Y. Lu and T. M. Link, "MRI of the Spine: Image Quality and Normal-Neoplastic Bone Marrow Contrast at 3 T versus 1.5 T," American Journal of Roentgenology, Vol. 192, No. 4, 2009, pp. 873-880. doi:10.2214/AJR.08.1750

[14] S. M. Erturk, A. Alberich-Bayarri, K. A. Herrmann, L. Marti-Bonmati and P. R. Ros, "Use of 3.0-T MR Imaging for Evaluation of the Abdomen," Radiographics, Vol. 29, No. 6, 2009, pp. 1547-1563. doi:10.1148/rg.296095516

[15] A. B. Rosenkrantz, J. M. Patel, J. S. Babb, P. Storey and E. M. Hecht, "Liver MRI at $3 \mathrm{~T}$ Using a RespiratoryTriggered Time-Efficient 3D T2-Weighted Technique: Impact on Artifacts and Image Quality," American Journal of Roentgenology, Vol. 194, No. 3, 2010, pp. 634641. doi:10.2214/AJR.09.2994

[16] C. Couinaud, "Liver Anatomy: Portal (and Suprahepatic) or Biliary Segmentation," Digestive Surgery, Vol. 16, No. 6, 1999, pp. 459-467. doi:10.1159/000018770

[17] M. A. Goldberg, P. F. Hahn, S. Saini, M. S. Cohen, P. Reimer, T. J. Brady and P. R. Mueller, "Value of T1 and T2 Relaxation Times from Echoplanar MR Imaging in the Characterization of Focal Hepatic Lesions," American Journal of Roentgenology, Vol. 160, 1993, pp. 1011-1017.

[18] C. L. Hoad, E. F. Cox and P. A. Gowland, "Quantification of T2 in the Abdomen at 3.0 T Using a T2-Prepared Balanced Turbo Field Echo Sequence," Magnetic Resonance in Medicine, Vol. 63, No. 2, 2010, pp. 356-364. doi: $10.1002 / \mathrm{mrm} .22203$

[19] T. C. Kwee, T. Takahara, T. Niwa, M. K. Ivancevic, G. Herigault, M. Van Cauteren and P. R. Luijten, "Influence of Cardiac Motion on Diffusion-Weighted Magnetic Resonance Imaging of the Liver," Magma, Vol. 22, No. 5, 2009, pp. 319-325. doi:10.1007/s10334-009-0183-1

[20] P. Murtz, S. Flacke, F. Traber, J. S. van den Brink, J. Gieseke and H. H. Schild, "Abdomen: Diffusion-Weighted MR Imaging with Pulse-Triggered Single-Shot Sequences," Radiology, Vol. 224, No. 1, 2002, pp. 258-264. doi:10.1148/radiol.2241011117

[21] J. Deng, R. A. Omary and A. C. Larson, "Multishot Diffusion-Weighted Splice Propeller MRI of the Abdomen," Magnetic Resonance in Medicine, Vol. 59, No. 5, 2008, pp. 947-953. doi:10.1002/mrm.21525

[22] H. Kandpal, R. Sharma, K. S. Madhusudhan and K. S. Kapoor, "Respiratory-Triggered versus Breath-Hold Diffusion-Weighted MRI of Liver Lesions: Comparison of Image Quality and Apparent Diffusion Coefficient Values," American Journal of Roentgenology, Vol. 192, No. 4, 2009, pp. 915-922. doi:10.2214/AJR.08.1260

[23] V. S. Lee, E. M. Hecht, B. Taouli, Q. Chen, K. Prince and N. Oesingmann, "Body and Cardiovascular MR Imaging at 3.0 T," Radiology, Vol. 244, No. 3, 2007, pp. 692-705. doi:10.1148/radiol.2443060582

[24] B. Taouli, A. Sandberg, A. Stemmer, T. Parikh, S. Wong, J. Xu and V. S. Lee, "Diffusion-Weighted Imaging of the Liver: Comparison of Navigator Triggered and Breathhold Acquisitions," Journal of Magnetic Resonance Imaging, Vol. 30, No. 3, 2009, pp. 561-568. doi:10.1002/jmri.21876

[25] M. von Siebenthal, G. Szekely, U. Gamper, P. Boesiger, A. Lomax and P. Cattin, "4D MR Imaging of Respiratory Organ Motion and Its Variability," Physics in Medicine and Biology, Vol. 52, No. 6, 2007, pp. 1547-1564. doi:10.1088/0031-9155/52/6/001

[26] K. Nasu, Y. Kuroki, H. Fujii and M. Minami, "Hepatic Pseudo-Anisotropy: A Specific Artifact in Hepatic Diffusion-Weighted Images Obtained with Respiratory Triggering," Magma, Vol. 20, No. 4, 2007, pp. 205-211. doi:10.1007/s10334-007-0084-0

[27] S. Colagrande, F. Pasquinelli, L. N. Mazzoni, G. Belli and G. Virgili, "MR-Diffusion Weighted Imaging of Healthy Liver Parenchyma: Repeatability and Reproducibility of Apparent Diffusion Coefficient Measurement," Journal of Magnetic Resonance Imaging, Vol. 31, No. 4, 2010, pp. 912-920. doi:10.1002/jmri.22117 